\title{
Economic Analysis of Small Size Gas Turbine Based CHP Plants in the Present Italian Context
}

\author{
Coriolano Salvini *, Ambra Giovannelli and Marco Varano \\ Department of Engineering, ROMA TRE University, via della Vasca Navale 79, Rome, Italy \\ Email: coriolano.salvini@uniroma3.it
}

\begin{abstract}
The paper deals with the economic performance assessment of CHP plants based on small size Gas Turbine (1-6 MWEL) taking the present Italian regulatory framework and economic context into consideration. From January 2011, the regulatory framework and, consequently, the incentive mechanism is radically changed. The "High Efficiency Cogeneration" concept has been introduced and requirements to be fulfilled by a CHP plant to obtain incentives defined. Such requirements are essentially related to the achievement of a threshold value of the Primary Energy Saving (PES) index. According to the new regulatory framework and taking the present national scenario into consideration (fuel and electricity prices, cost of money, etc.), a technoeconomic analysis aimed at assessing the viability and suitability of installing GT based small CHP plant has been carried out. The convenience of the investment has been assessed by comparing costs incurred by installing and operating the CHP plant with those related to the purchase of the required electric power and the production of heat in a fuel fed boiler. Several CHP plant arranged with commercially available MW-class GTs have been examined. Results show that plants in the range of 1.5-6 MWEL can lead to relevant cost savings. For lower sizes, the investment effectiveness has to be carefully checked.
\end{abstract}

Keywords: CHP plants, Gas turbine with heat recovery, Small size gas turbine, High efficiency cogeneration.

\section{INTRODUCTION}

Cogeneration consists in the simultaneous combined production of two or more energy carriers (i. e. electricity, hot fluids, cold fluids, etc.) in the same plant by using a primary energy source. The most diffused cogeneration plants are CHP plants (Combined Heat and Power), where the energy content of a fuel is converted into electricity and useful heat. Heat is commonly provided to the final user as saturated/superheated steam or hot water produced in the plant. The nature of the adopted heat carrier and delivery pressure and temperature are chosen according to the features of the process to be accomplished (e. g. industrial process heating, district heating, cold production from heat in absorption groups, etc.). The produced electricity can be selfconsumed to satisfy the needs of the site where the CHP plant is installed (industrial plants, large housing estates, shopping malls, etc.) or exported to the national grid.

CHP systems are largely employed worldwide. The main reason of such a diffusion is the capability of CHP plants of reducing the amount of fuel required to produce given amounts of electricity and heat in respect to that required by separate generation systems. The Primary Energy Saving (PES), when suitable conditions exist, can lead to significant cost reduction in respect to the common practice consisting in purchasing electricity from the grid and producing heat in a fuel fed boiler. Moreover, the reduction of fuel consumption brings to global advantages in terms of emission reduction and of domestic energy security for that countries strongly dependent on fossil fuels imports, such as Italy. As a result, as an efficient and well established way to save primary energy, cogeneration is supported and incentivized by European Community [1] and other Governments worldwide. Therefore, further economic benefits can be achieved if the CHP plants performance matches the criteria laid down in the local regulatory framework.

In Italy, the 2013 electric and heat production (last available data) from CHP plants has been of some 91,300 and $59,100 \mathrm{GWh}$ respectively [2]. To put in evidence the role and the weight of cogeneration in the Italian electric system, the CHP electric production in year 2013 accounted for some $47 \%$ of the overall national production from fossil fueled plants (192,986 GWh, [2]).

About $80 \%$ of CHP electricity is generated by Gas-Steam Combined Cycles with Steam Extractions (GSCC-SE). Internal Combustion Engines with Heat Recovery (ICE-HR) account for $12 \%$ of the overall electric production. Steam Condensing Turbines with Steam Extractions (SCT-SE) and Gas Turbines with Heat Recovery (GT-HR) show a production share of some $5 \%$ and $4 \%$ respectively. Finally, Steam Back Pressure Turbines (SBPT) contribute with the remaining $2 \%$. 
The useful heat production sharing is somewhat different according to the typical features of the different plant concepts under consideration: 50\% from GSCC-SE, $20 \%$ from SCT-SE, the remainder $30 \%$ almost equally distributed among ICE-HR, SBPT and GT-HR.

The most recent official reports about the status of cogeneration in Italy refer to year 2013 [3, 4]. Statistics have been produced taking into account only those CHP plants for which an incentive request was submitted to the Competent Authority. Electricity and heat produced by the CHP plants under consideration are 55,019 and 31,331 GWh respectively, i. e. $60 \%$ and $53 \%$ of the overall national values reported in [2]. Therefore, data presented in [3] give a representative picture of the overall National CHP pool. Anyway, it has to be pointed out that efficiency data reported in [3] are higher than those evaluated by using overall national data given in [2]. Such differences are remarkable for SBPT (85.9 vs $77.3 \%)$, ICE-HR (70.3\% vs $61.6 \%)$ and GT-HR (79.6\% vs 70.7\%). Therefore, for the above CHP plant categories, only the better performing plants are taken into consideration, i. e. those eligible for incentives provided for achieving a defined efficiency target.

Available data refer to $1,025 \mathrm{CHP}$ plants for an overall installed electric capacity of 13,087 MW:

- $\quad$ GSCC-SE: 67 plants, 11,100 $\mathrm{MW}_{\mathrm{EL}}$;

- $\quad$ ICE-HR: 898 plants, $994 \mathrm{MW}_{\mathrm{EL}}$;

- $\quad$ SCT-SE: 3 plants, $196 \mathrm{MW}_{\mathrm{EL}}$;

- GT-HR: 53 plants, $340 \mathrm{MW}_{\mathrm{EL}}$

- $\quad$ SBPT: 4 plants, $130 \mathrm{MW}_{\mathrm{EL}}$;

- $\quad$ other kinds of plants: 20plants, $314 \mathrm{MW}_{\mathrm{EL}}$

GT-HR represent some $2.6 \%$ of the overall installed power and account for some $8 \%$ of heat and $3 \%$ of electricity produced by CHP.

The GT-HR average plant size is around $6 \mathrm{MW}_{\mathrm{EL}}$, being larger GTs most conveniently employed in GSCC-SE arrangement and smaller sizes (1 MW $\mathrm{ML}_{\mathrm{EL}}$ or less) monopolized by ICE-HR. Such plants are featured by electrical efficiencies (the ratio between electric output and fuel input) ranging from 24 to $35 \%$ and can provide high temperature thermal energy $\left(500-550^{\circ} \mathrm{C}\right)$ to produce useful heat. The reported GT-HR average cogeneration efficiency is really high, overtaken only by SBPT plants. It has to be pointed out that such high cogeneration efficiencies can be achieved only if the user requires continuously large amounts of high temperature heat. Such condition is in practice fulfilled only by industrial users, being applications in domestic or tertiary sectors usually featured by large electric and thermal load fluctuations along the time $[5,6]$.

In the present paper, a techno economic analysis aimed at assessing the economic performance of CHP plants based on small size Gas Turbine (1-6 $\mathrm{MW}_{\mathrm{EL}}$ ) is performed taking the present Italian context into consideration (regulatory framework, incentives, fuel and electricity prices, cost of money, etc.). The development potentialities of GT-HR plants in the present and future scenarios are analyzed on the basis of available sectoral studies. GT-HR plants economic performance is evaluated by comparing costs incurred by installing and operating the CHP plant with those related to the purchase of the required electric power and the production of heat in a fuel fed boiler. Several CHP plant arranged with commercially available MW-class GT are taken into consideration. A techno-economical model has been developed to evaluate plant technical performance, investment and operating costs. Finally results are given and widely discussed.

\section{THE PRESENT ITALIAN CONTEXT}

The first reference to cogeneration in the Italian Legal Framework can be found in the Decree December 6, 1962 n.1643. Nevertheless, the first specific regulation was given only in $80^{\prime}$. In particular, exhaust heat from industrial processes and from power plants was equated with renewable energy sources (Act n.308/82 and CIP Directive n. 15/89). Then, the CIP Directive n. 34/90 established how evaluate the energy saving from cogeneration. Such an evaluation was based on CHP plant nominal performance (without taking into account plant performance reduction due to off-design running conditions or plant deterioration). Such evaluation had been modified and improved later. The Decree May 7, 1992 provided a Merit Parameter to evaluate incentives. However, such a parameter was inadequate because it could be overtaken by plants with low performance.

The CIP Directive (n.6/92) fixed new criteria to equate exhaust heat to renewable energies, providing an energetic index called IEN (National Energetic Index) derived from PES by introducing reference efficiency values for separate generation. The Directive established that IEN should be $\geq$ 0.51 . Thus, the Directive favored especially the electricity production from large plants (combined plants) instead of small-medium cogeneration plants. After all, the Act n.9/91 and the CIP Directive n.6/92 were issued while there were a high electricity demand in the national market and an insufficient electricity production.

Hereafter, the Decree n. 79/99 established a priority for the production by renewable energy and cogeneration, on the basis of specific criteria detailed by the Competent Authority through the years (Directive March 19, 2002 n. 42/02). In particular there was the introduction of two relevant parameters: the "Energy Saving Index" (IRE) and the "Thermal Limit" (TL). Minimum values for both of them were fixed and reviewed later.

In 2007 (Legislative Decree February 8, 2007, [7]) Italy brought into force the Directive 2004/8 EC adopted by the European Parliament and the Council of the European Union, introducing the innovative concepts of "Electricity from Cogeneration $\left(E_{C H P}\right)$ and "Primary Energy Savings" (PES). In the National context, procedures for their evaluation were given by means of the Ministerial Decree August 4, 2011. In such a manner, various benefits were granted to the "High Efficiency Cogeneration" (HEC):

- the dispatching priority of the electricity generated by cogeneration plants in respect to production based on conventional commodities (art. 11 Legislative Decree n.79 March 16, 1999);

- the access to the Green Papers for cogeneration plants coupled with the district heating (Art. 14 Legislative Decree n.20 February 8, 2007);

- the access to the White Papers (Ministerial Decree September 5, 2011);

- tax breaks for the gas fuel used for cogeneration (Legislative Decrees n. 504 October 26, 1995 and n. 26 February 2, 2007);

- net metering for High Efficiency Cogeneration plants with nominal power up to $200 \mathrm{~kW}$ (Authority Directive June 3, 2008);

- the support under feed-in schemes like renewable energy plants;

- $\quad$ specific tax exemptions.

Moreover, in addition to the legislative context, the changes in the National Electricity Market in the same years 
have to be taken into consideration. While in 90' electricity demand was high and the production insufficient, the recent global economic crisis has led to a downward trend to electricity demand (e.g. -2.5\% from 2013 to 2014) [8]. Such a depletion has been engaged in the same period of the growth in electricity production from renewable energy sources (e.g. $+7.7 \%$ from 2013 to 2014). Meanwhile, in 2014 the gas price has stopped its growth, coming back to the level of 2010 and the oil price collapsed in the last quarter of 2014.

The development potentialities of HEC in the present legislative and economic context are analyzed in [4]. According to such a study, the most energy consuming industrial sectors (i. e. oil refining, steel and iron industry, paper mills) have reached and exceeded the CHP technical development potentiality related to the electric production capacity. This is a consequence of the past years scenarios featured by: i) a higher cost of electricity in respect of the present one; ii) the possibility to export electricity to the National grid to manage imbalances between user's thermal and electrical demand. It has to be pointed out that the supply of electricity to the grid was in the past well remunerated; iii) the wholesale of electricity as an integration of the industry core business.

As stated before, the present scenario is featured by an excess of installed power and a by reduction of the electricity demand from fossil fuels. As a consequence, it is reasonable to assume in the industrial sector a restructuration or a shift towards CHP plants featured by higher heat production capabilities, i. e. lower electricity to useful heat ratios. It is therefore expected that in the future GSCC-SE and SCT-SE will be to some extent replaced by GSCC-SBPT (Gas Steam Combined Cycle with Steam Back Pressure Turbine), SBPT and GT-HR.

\section{HIGH EFFICIENCY COGENERATION REQUIREMENTS FOR GAS TURBINE WITH HEAT RECOVERY PLANTS}

General criteria and calculation procedures to assess HEC parameters are given in [9]. For sake of brevity, the description here reported is addressed only to $\mathrm{MW}_{\mathrm{EL}}$-class GT-HR plants without supplementary firing.

As previously stated, the Annex II of EU Directive 2004/8 introduces the concept of "Electricity from Cogeneration" $E_{C H P}$. For a given CHP plant, such an electricity represents the fraction of the overall electricity production $E$ directly linked to the useful heat $H_{C H P}$ delivered to the user. $E_{C H P}$ can be equal or lesser than $E$ depending on the value assumed by the plant global cogeneration efficiency $\eta_{G, C H P}$ :

$\eta_{G_{\mu} C H P}=\left(E+H_{C H P}\right) / F$

where $F$ represents the fuel energy input. If $\eta_{G, C H P}$ equals or exceeds the threshold value established for GT-HR plants (0.75), all the produced electricity is recognized as "from cogeneration" and consequently $E_{C H P}=E$. Otherwise, the real plant is virtually split into two parts: the first operating in cogeneration regime with $\eta_{G, C H P}=0.75$, the second one in non-cogeneration mode. According to the procedure illustrated in [7], the following quantities related to the cogeneration part of the plant are calculated:

- $E_{C H P}$, previously defined;
- $\quad F_{C H P}$, representing the fuel input required by the cogeneration part of the plant to produce $H_{C H P}$ and $E_{C H P}$.

Such quantities allow the calculation of the thermal cogeneration efficiency $\eta_{H, C H P}$ :

$\eta_{H_{C H P}}=H_{C H P} / F_{C H P}$

and the electric cogeneration efficiency $\eta_{E, C H P:}$

$\eta_{E_{C H P}}=E_{C H P} / F_{C H P}$

Finally, the Primary Energy Saving PES is evaluated:

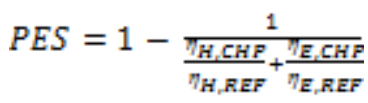

where $\eta_{H, R E F}$ and $\eta_{E, R E F}$ are the efficiency reference values for thermal and electric separate production. Such values are established taking into account the best available and economic viable technologies for separate generation of heat and electricity. Efficiency reference values were firstly published in 2006 by EU, and subsequently updated according to technology improvements. Suitable corrections factors are introduced to account for site temperature, used fuel, grid voltage and self-consumed to grid exported electricity ratio.

The GT-HR plant is recognized as a HEC plant if PES reaches a threshold value of 0.1 .

\section{GAS TURBINE WITH HEAT RECOVERY TECHNO-ECONOMIC MODEL}

The plant reference scheme is given in Figure 1. GT exhaust gases available at TOT (Turbine Outlet Temperature) are fed to a Heat Recovery Steam Generator (HRSG) where saturated or slightly super-heated steam is produced at a fixed pressure level. Such steam is supplied to a heat transfer device where useful heat $H_{C H P}$ is provided to the final user (e. g. an industrial process). The condensate is then returned to the HRSG.

As previously stated, analyses carried out in the present work are focused on GT-HR plants featured by an electrical output up to $6 \mathrm{MW}_{\mathrm{EL}}$. GTs covering the power band of interest have been selected among those available on the market. Data concerning the selected machines (taken from [10]) are reported in Tab.1.

It can be noticed that nominal electrical efficiency $\eta_{E L, I S O}$ increases with the nominal rated power $P_{E L, I S O}$ from $24 \%$ to $31 \%$. Such values are relatively low in comparison to those featuring larger size GTs.

Solar Mercury 50 recuperated GT is the exception, showing a noticeable $38.5 \%$ efficiency value. The different design philosophies are evidenced by efficiency and TOT values. GTs manufactured by Kawasaki show values within a really narrow interval $\left(520-540^{\circ} \mathrm{C}\right)$. Conversely, Solar machines TOT $_{\mathrm{s}}$ range from 365 to $510^{\circ} \mathrm{C}$.

\subsection{CHP plant technical model}

A simple GT technical model has been developed on the basis of data provided by manufacturer elaborated to account for relevant issues affecting GT performance along the time. 


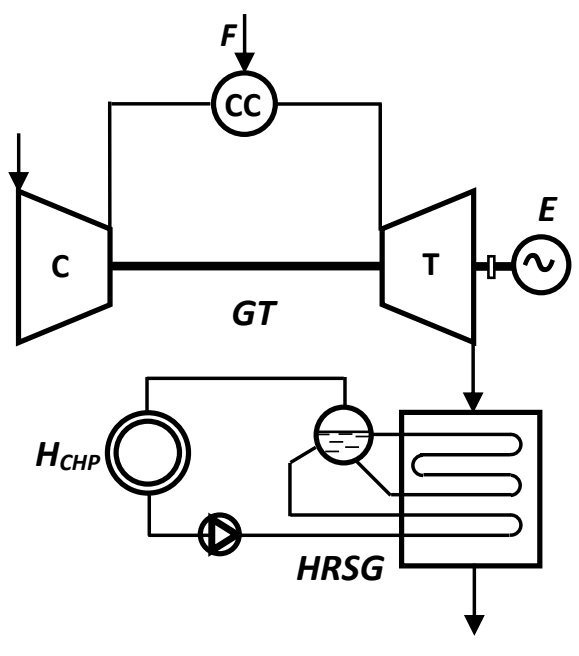

Figure 1. GT-HR plant scheme

Data given in Table 1 refer to ISO ambient standard conditions $\left(15^{\circ} \mathrm{C}, 101.3 \mathrm{kPa}, 60 \%\right.$ relative humidity). It is assumed that plants are installed at sea level. Therefore, calculations are carried out by assuming an ambient pressure of $101.3 \mathrm{kPa}$. Plants are operated at baseload (or close to baseload) conditions. The possibility of achieving such a target is confirmed by data reported in [3]: 2013 annual average electrical efficiency of GT-HR plants is around $31 \%$. Taking into consideration that the average plant size is of some $6 \mathrm{MW}_{\mathrm{EL}}$, such an efficiency value is not so far from nominal design values usually shown by small size GTs.

GT baseload power and electrical efficiency are affected by the ambient air temperature $T_{A M B}$. By increasing $T_{A M B}$, both baseload power and efficiency show a decreasing trend.

Therefore, $\mathrm{j}$-th year average baseload electric power and efficiency are evaluated according to (5) and (6):

$$
\begin{gathered}
P_{E L_{i j} j}=P_{E L_{i} I S 0} \times u_{p} \times\left(1-\frac{\Delta P_{j}}{100}\right) \\
\eta_{E L_{j} j}=\eta_{E L_{j} I S 0} \times u_{\eta} \times\left(1-\frac{\Delta \eta_{j}}{100}\right)
\end{gathered}
$$

being $P_{E L, I S O}$ and $\eta_{E L, I S O}$ nominal baseload value reported in Table 1 . The $\mathrm{j}$-th year electricity production is obtained by multiplying $P_{E L, j}$ by the annual operating hours $h_{j}$. Annual fuel consumption $m_{F, j}$ is given by:

$$
m_{F_{j} j}=\left(h_{j} \times P_{E L_{i j} j}\right) /\left(\eta_{E L_{i j} j} \times H_{F}\right)
$$

Being $H_{F}$ the fuel heating value.

To take the annual temperature variation into account, averaged baseload power and efficiency have been estimated by introducing two corrective coefficients $\left(u_{P}\right.$ and $u_{\eta}$ ) set up on the basis of a typical annual temperature pattern and typical GT performance trends versus ambient temperature. The coefficient $u_{P}$ reduce the ISO baseload power, $u_{\eta}$ the electrical efficiency. Adopted values are given in Table 2.

Another relevant issue to take into consideration in estimating the electricity production along the time is related to the GT performance decay [11]. Both baseload power and efficiency show a reduction due to deterioration phenomena

\begin{tabular}{|c|c|c|c|c|}
\hline GT MODEL & $\begin{array}{c}\text { PEL,ISO } \\
{[\mathrm{kW}]}\end{array}$ & $\begin{array}{c}\eta_{\mathrm{EL}, \mathrm{ISO}} \\
{[\%]}\end{array}$ & $\begin{array}{l}\text { TOT } \\
{\left[{ }^{\circ} \mathrm{C}\right]}\end{array}$ & $\begin{array}{r}\text { Exhaust flow } \\
{\left[\mathrm{x} 10^{3} \mathrm{~kg} / \mathrm{hr}\right]}\end{array}$ \\
\hline GPB15D $^{1}$ & 1,490 & 24.0 & 531 & 28.8 \\
\hline GPB17D ${ }^{1}$ & 1,690 & 26.6 & 521 & 29.1 \\
\hline GPB30D $^{1}$ & 2,930 & 23.6 & 531 & 57.6 \\
\hline GPB60D $^{1}$ & 5,400 & 29.2 & 542 & 78.3 \\
\hline Saturn $20^{2}$ & 1,210 & 24.3 & 505 & 23.5 \\
\hline Centaur $40^{2}$ & 3,515 & 27.9 & 445 & 68.4 \\
\hline Centaur $50^{2}$ & 4,600 & 29.3 & 510 & 68.7 \\
\hline Mercury $50^{2}$ & 4,600 & 38.5 & 365 & 63.7 \\
\hline Taurus $60^{2}$ & 5,670 & 31.5 & 510 & 78.4 \\
\hline
\end{tabular}
(fouling, erosion, etc) occurring during plant operation.
Table 1. Gas Turbines data

Table 2. GT power and efficiency loss coefficient

\begin{tabular}{|c|c|c|c|}
\hline \multicolumn{2}{|c|}{ Power } & \multicolumn{2}{c|}{ Efficiency } \\
\hline $\mathrm{uP}_{\mathrm{P}}[-]$ & 0.90 & $\mathrm{u}$ & 0.95 \\
\hline$\Delta \mathrm{P}_{1}[\%]$ & 2.25 & $\Delta \eta_{1}[\%]$ & 1.10 \\
\hline$\Delta \mathrm{P}_{2}[\%]$ & 3.85 & $\Delta \eta_{2}[\%]$ & 1.90 \\
\hline$\Delta \mathrm{P}_{3}[\%]$ & 4.50 & $\Delta \eta_{3}[\%]$ & 2.23 \\
\hline$\Delta \mathrm{P}_{4}[\%]$ & 4.85 & $\Delta \eta_{4}[\%]$ & 2.40 \\
\hline$\Delta \mathrm{P}_{5}[\%]$ & 5.10 & $\Delta \eta_{5}[\%]$ & 2.45 \\
\hline$\Delta \mathrm{P}_{6}[\%]$ & 5.25 & $\Delta \eta_{6}[\%]$ & 2.50 \\
\hline
\end{tabular}

On the basis of manufacturer's information, reduction coefficients accounting for GT annual loss of performance have been introduced.

Table 2 gives the power and efficiency loss coefficients ( $\Delta P_{j}$ and $\Delta \eta_{j}$ respectively) for the $\mathrm{j}$-th year of operation.

A simplified sizing procedure has been developed to estimate quantities required to assess HRSG performance and cost. The HRSG is assumed to be made by two tube bundles, i.e. the evaporator and the economizer. For each CHP plant under consideration, saturated steam is produced at 10 bar (saturation temperature equal to $179^{\circ} \mathrm{C}$ ). Condensate return temperature is set at $50^{\circ} \mathrm{C}$. The sizing has been performed according to the following conditions:

a) minimum pinch-point temperature difference equal to $20^{\circ} \mathrm{C}$;

b) minimum gas exit temperature set at $130^{\circ} \mathrm{C}$.

Isobaric gas specific heat is calculated as a function of temperature and GT air/fuel ratio (estimated on the basis of Table 1 data) by adopting a polynomial formulation. Gas and steam/water temperature profiles, exchanged thermal power and steam mass flow rate are evaluated by applying to each tube bundle mass and energy conservation equations under the constraints imposed by the fulfilment of conditions a) and b). The approach adopted to determine the HRSG investment costs requires the evaluation of the product $U \times A$ for each tube bundle, being $U$ and $A$ the bundle overall heat transfer coefficient and heat transfer area respectively. For the generic tube bundle, the value of $U \times A$ is given by the formula:

$(U \times A)_{\text {bundle }}=Q_{\text {bundle }} / L M T D_{\text {bundle }}$ 
Table 3. CHP plant design data

\begin{tabular}{|l|c|c|c|c|c|c|}
\hline $\begin{array}{l}\text { GT } \\
\text { MODEL }\end{array}$ & $\begin{array}{c}\text { PEL,ISO } \\
{[\mathrm{kW}]}\end{array}$ & $\begin{array}{l}\text { QTH,ISO } \\
{[\mathrm{kW}]}\end{array}$ & $\begin{array}{c}(\mathrm{UA})_{\text {EC }} \\
{[\mathrm{kW} / \mathrm{K}]}\end{array}$ & $\begin{array}{l}(\mathrm{UA}) \text { EV } \\
{[\mathrm{kW} / \mathrm{K}]}\end{array}$ & $\begin{array}{c}\text { E/H } \\
{[--]}\end{array}$ & $\begin{array}{c}\eta \text { CHP } \\
{[\%]}\end{array}$ \\
\hline GPB15D & 1,490 & 3,499 & 11.7 & 21.2 & 0.42 & 80.3 \\
\hline GPB17D & 1.690 & 3,433 & 11.7 & 21.8 & 0.49 & 80.6 \\
\hline GPB30D & 2,930 & 6,998 & 23.3 & 42.2 & 0.42 & 80.0 \\
\hline GPB60D & 5,400 & 9,817 & 32.0 & 57.0 & 0.55 & 82.3 \\
\hline Saturn 20 & 1,210 & 2,665 & 9.5 & 18.1 & 0.43 & 78.0 \\
\hline Centaur 40 & 3,515 & 6,268 & 22.7 & 53.2 & 0.56 & 77.6 \\
\hline Centaur 50 & 4,600 & 7,913 & 27.7 & 52.5 & 0.58 & 79.7 \\
\hline Mercury 50 & 4,600 & 3,898 & 12.4 & 42.3 & 1.18 & 71.1 \\
\hline Taurus 60 & 5.670 & 9,033 & 31.7 & 59.9 & 0.63 & 81.7 \\
\hline
\end{tabular}

being $Q_{\text {bundle }}$ the thermal power exchanged in the bundle and $L M T D_{\text {bundle }}$ the logarithmic mean temperature difference.

Results of sizing are given in Table 3. All the plants taken into consideration - with the exception of the Mercury 50 plant - show a design cogeneration efficiency above the HEC threshold. For both Kawasaki and Solar Turbines GT based plants, the electricity to heat ratio $E / H$ increases with nominal electric power. It can be noticed that $E / H$ ratios featuring Solar Turbines based plants are somewhat higher than those shown by plants arranged with Kawasaki GTs. Finally, due to the GT peculiar characteristics, the Mercury 50 plant performance data differ significantly from those of the other plants, especially in terms of $E / H$ ratio. It has to be pointed out that such a plant is the only one showing a cogeneration efficiency below 0.75 .

\subsection{Economical model}

The assessment of GT based CHP plants economic performance requires the determination of both capital and operating costs.

GT investment cost estimation has been carried out on the basis of prices reported in [8]. Such prices (given in 2009 US dollars) have been converted into Euros and updated by applying the Marshall\&Swift - Equipment Average Index. Further, the above prices have been corrected by assuming suitable additional cost factors to account for:

- local prices and shipping. Prices provided in [10] refer essentially to the US market. Therefore, such prices have been corrected on the basis on available sellers' tenders for small size GT supplies to Italian customers. As a result, an additional cost factor of $30 \%$ has been applied;

- installation costs, including foundations, electrical equipment, labor, engineering, contractor's fee, etc. A cost additional factor of $38 \%$ has been assumed.

To determine the HRSG investment cost, the approach proposed by Foster-Pegg in 1989 [12] has been adopted. Since the original formulation is addressed to large size HRSGs, it has been suitably modified for small size ones by using available manufacturers' cost data. The HRSG base cost (given in 2004 thousands of Euro) is expressed as the sum of three terms:

$C_{\text {HASG }}=C_{\text {HTS }}+C_{\text {STEAM }}+C_{\text {GAS }}$

The term $C_{H T S}$ is related to the extension of the required heat transfer surfaces:

$$
C_{H T S}=K_{H T S} \times\left[(U \times A)_{E V}{ }^{0.9}+(U \times A)_{E C}{ }^{0.8}\right]
$$

where products $U \times A$ referring to evaporator and economizer tube bundles are expressed in $\mathrm{kW} / \mathrm{K}$ and constant $K_{H T S}$ is equal to 12.15 .

The term $C_{\text {STEAM }}$ accounts for piping and other devices required for steam management (valves, headers, etc). It is proportional to the produced steam mass flow rate $m_{S T E A M}$ (expressed in $\mathrm{kg} / \mathrm{s}$ ):

$C_{\text {STEAM }}=K_{\text {STEAM }} \times m_{\text {STEAM }}$

where $K_{S T E A M}=0.7$. Finally, $C_{G A S}$ takes into consideration costs related to HRSG enclosure, insulation, main and bypass stacks and other devices required to ensure the gas circulation:

$C_{\text {GAS }}=K_{\text {GAS }} \times m_{\text {GAS }}^{1.2}$

being $m_{G A S}$ the gas mass flow rate and $K_{G A S}=0.825$.

To estimate the HRSG installed cost, a cumulative additional cost factor of $44 \%$ has been applied. Such factor takes into account direct and indirect installation costs as well as contingencies. The value has been set according to available manufacturer data.

Apart of the cost of fuel (discussed in the next section), further plant operating cost items have been taken into consideration:

- $\quad$ routine maintenance costs, assumed to be $13 €$ per hour of GT operation on the basis of manufacturers' information;

- $\quad$ monitoring and operation of the plant: $26,000 €$ per year;

- $\quad$ insurance, $0.134 \mathrm{c} €$ per produced kilowatt-hour.

\subsection{Fuel, electricity and White Papers}

The assessment of GT based CHP plants economic viability has been carried out by evaluating the achievable cost savings in respect to the common practice consisting in producing steam in a fuel fed boiler and purchasing electricity from the grid. Therefore, reference prices for fuel Natural Gas (NG) and electricity have been set up.

CHP plants are assumed fueled with Natural Gas (NG) with a Lower Heating Value $H_{F}=48,377 \mathrm{~kJ} / \mathrm{kg}$. NG cost has been evaluated by assuming an after-tax price of $31.5 \mathrm{c} € / \mathrm{scm}$, in agreement with data reported [4]. The application of excise duties and VAT leads to a final price of $36 \mathrm{c} € / \mathrm{scm}$. If fuel is used in a CHP plant, the excise duties are calculated in agreement to the HEC regulatory and local framework

A price of $14 \mathrm{c} € / \mathrm{kWh}$ has been assumed for electricity, taking again data provided in [4] as a reference

As reported in [13], CHP plants could benefit of a further support mechanism constituted by White Papers issued in proportion to the amount of primary energy saved $\left(E_{S A V}\right)$ during each year of operation:

$E_{S A V}=\frac{E_{C H P}}{\mathbb{R}_{E, R I F}}+\frac{H_{C H P}}{\mathbb{R}_{T, R I F}}-F_{C H P}$

The energy saving is converted into the number of White Papers $N_{W P}$ according to the formula:

$N_{W P}=0.086 \times E_{\text {SAV }} \times K$

being 0.086 the conversion factor from MWh to TOE and $K \mathrm{a}$ factor depending on the size of the plant. Since the size of 
CHP plants taken into consideration in the present work ranges from 1 to $6 \mathrm{MW}_{\mathrm{EL}}, K$ is equal to 1.3 . Presently, the value of a White Paper is of some $100 €$.

\section{TECHNO-ECONOMIC ANALYSIS RESULTS AND DISCUSSION}

Analyses have been carried out in the perspective of installing a GT based CHP plant to provide electricity and steam to an industrial user. It is assumed that electricity was formerly purchased from the grid and steam was produced in a NG fueled steam generator. The convenience of the investment is assessed by evaluating possible cost savings in respect to the existing original situation.

The study has been carried out according to following assumptions:

a) the produced electricity is integrally self-consumed in the industrial plant served by the CHP plant ;

b) all the producible heat is absorbed by the user;

c) CHP plants are fuelled with NG;

d) medium voltage connection to the electric grid;

e) 7,500 annual operating hours;

f) annual discount rate $i=5 \%$.

Assumptions a), b), c) and d) lead to the definition to thermal and electric reference efficiencies for separate generation according to [9]: $\eta_{H, R E F}=0.9$ and $\eta_{E, R E F}=0.4856$.

Annual money savings are evaluated as:

$$
\Delta C_{\text {SAV }}=\left(C_{F_{1} B O H}+C_{E_{N} \text { PNCH }}\right)-\left(C_{F_{K C H P}}+C_{O P, C H P}-C_{W P}\right)
$$

where:

- $C_{F, B O I L}$ represents the cost of fuel required to produce the useful heat $\mathrm{H}_{\mathrm{CHP}}$ in a steam generator;

- $C_{E, P U R C H}$ is the cost incurred to purchase from the grid an amount of electricity equal to $E_{\mathrm{CHP}}$;

- $C_{F, C H P}$ is the cost of fuel consumed in the CHP plant to produce $E_{\mathrm{CHP}}$ and $\mathrm{H}_{\mathrm{CHP}}$, evaluated taking tax reduction (if achieved) into consideration;

- $\quad C_{O P, C H P}$ expresses the CHP plant other operating costs (i. e. routine maintenance, plant monitoring and operation, insurance).

- $\quad C_{W P}$, the value of White Papers (if achieved).

The viability of the investment has been assessed through typical indexes such as Present Net Value $(P N V)$, Discounted Profitability Index $(D P I)$ and Pay-Back Time $(P B T)$. Here, $P N V$ and $D P I$ at $\mathrm{N}$-th year are calculated as follows:

$$
\begin{aligned}
& P N V_{N}=-C_{U N V}+\sum_{j=1}^{N}\left[\Delta C_{S A V_{i j} j} /(1+i)^{j}\right] \\
& D P I_{N}=\sum_{j=1}^{N}\left[\Delta C_{S A V_{i j} j} /(1+i)^{j}\right] / C_{I N V}
\end{aligned}
$$

being $C_{I N V}$ the CHP plant investment cost.

The economic performance has been evaluated taking a five year time horizon into consideration. Plant life durations are, of course, much higher. Anyway, taking the present context uncertainties and contingencies into account, a short time period analysis has been found appropriate.

Results are summarized in Table 4. All the plants reach a positive $P N V$ after five years of operation. It can be noticed that the smaller plant (based on Saturn 20 GT) is just over the profitability threshold. Moreover, it is the only plant unable to meet the HEC requirements.
Table 4. Economic Analysis results

\begin{tabular}{|c|c|c|c|c|c|c|}
\hline $\begin{array}{c}\text { GT } \\
\text { MODEL }\end{array}$ & $\begin{array}{c}\text { CINV } \\
{[\mathrm{k} €]}\end{array}$ & $\begin{array}{c}\text { PNV } \\
{[\mathrm{k} €]}\end{array}$ & $\begin{array}{c}\text { DPI } \\
{[--]}\end{array}$ & $\begin{array}{c}\text { PBT } \\
{[\mathrm{y}]}\end{array}$ & $\begin{array}{c}\text { PES } \\
{[\%]}\end{array}$ & $\begin{array}{c}\mathrm{N}_{\mathrm{WC}} \\
{[-]}\end{array}$ \\
\hline GPB15D & 2,438 & 1,030 & 1.42 & 3 & 11.5 & 971 \\
\hline GPB17D & 2.648 & 1,439 & 1.54 & 3 & 13.5 & 1158 \\
\hline GPB30D & 4,139 & 3,048 & 1.74 & 3 & 10.9 & 1854 \\
\hline GPB60D & 6,479 & 8,158 & 2.26 & 2 & 16.2 & 4033 \\
\hline Saturn 20 & 2,079 & 0,074 & 1.04 & 5 & 9.3 & 0 \\
\hline Centaur 40 & 4,752 & 3,629 & 1.76 & 3 & 11.5 & 2066 \\
\hline Centaur 50 & 5,781 & 5,945 & 2.03 & 3 & 14.1 & 3059 \\
\hline Mercury 50 & 5,514 & 4,271 & 1.77 & 3 & 15.0 & 3021 \\
\hline Taurus 60 & 6.635 & 8,610 & 2.3 & 2 & 17.0 & 4173 \\
\hline
\end{tabular}

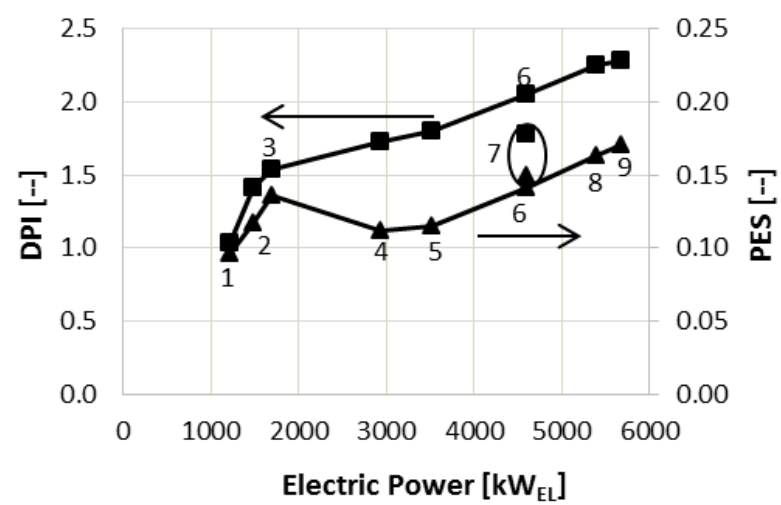

LEGEND: 1-Saturn 20; 2-GPB15D; 3- GPB17D; 4-GPB30D; 5Centaur 40; 6-Centaur 50; 7-Mercury 50; 8-GPB60D; 9-Taurus 60

Figure 2. DPI and PES versus installed electric power

Technical and economic performance indexes (PES and $D P I$ respectively) versus plant reference electrical power $P_{E L, I S O}$ are shown in Figure 2. Some plants (2, 4 and 5) show $P E S$ values really close to the threshold for achieving HEC incentives.

Therefore, HEC benefits could be easily lost if less favorable plant operations are assumed, e.g. a partial utilization of the producible heat. Such issue will be discussed later in the paper. Economic performance improves with the size of the plant. Such an improvement is mainly related to the reduction of the plant specific investment cost and, secondarily, to the increase of plant technical performance. On the basis of Table 4 data, plant specific investment costs decrease of about $30 \%$ as $P_{E L, I S O}$ increases from 1,210 to $5,670 \mathrm{~kW}$. As a result, small size plants economic performance is severely penalized by the augmented investment costs.

To get an idea of how the investment cost can affect the economic performance, the DPI of GPB15D based plant has been re-calculated by assuming the GPB60D plant specific investment cost. In Table 5, GPB15D actual and re-calculated data are compared with those of GPB60D one. To take into consideration the influence of different GT features, technical performance data are also reported.

GPB60D plant shows a DPI actual value some $60 \%$ higher than that the GPB15D one. By assuming for both plants the same specific investment cost (i. e. 1,200 €/kW), the difference reduces to $16 \%$. This residual difference is due to the higher annual cost savings resulting from the higher GPB60D efficiency and $E / H$ ratio. 
Table 5. GPB15D and GPB60D performance comparison

\begin{tabular}{|l|c|c|c|}
\hline & GPB15D & GPB60D & $\Delta[\%]$ \\
\hline PEL,ISo [kW] & 1,490 & 5,400 & +262 \\
\hline$\eta_{\text {EL,ISo }[\%]}$ & 24.0 & 29.2 & +22 \\
\hline E/H [--] & 0.42 & 0.55 & +31 \\
\hline$\eta_{\text {CHP }[\%]}[80.3$ & 82.3 & +2.5 \\
\hline PES [\%] & 11.5 & 16.2 & +41 \\
\hline CINV,SP [€/kW] & 1,636 & 1,200 & -27 \\
\hline DPI -Actual [--] & 1.42 & 2.26 & +59 \\
\hline DPI @ 1200 €/kW. [--] & 1.94 & 2.26 & +16 \\
\hline
\end{tabular}

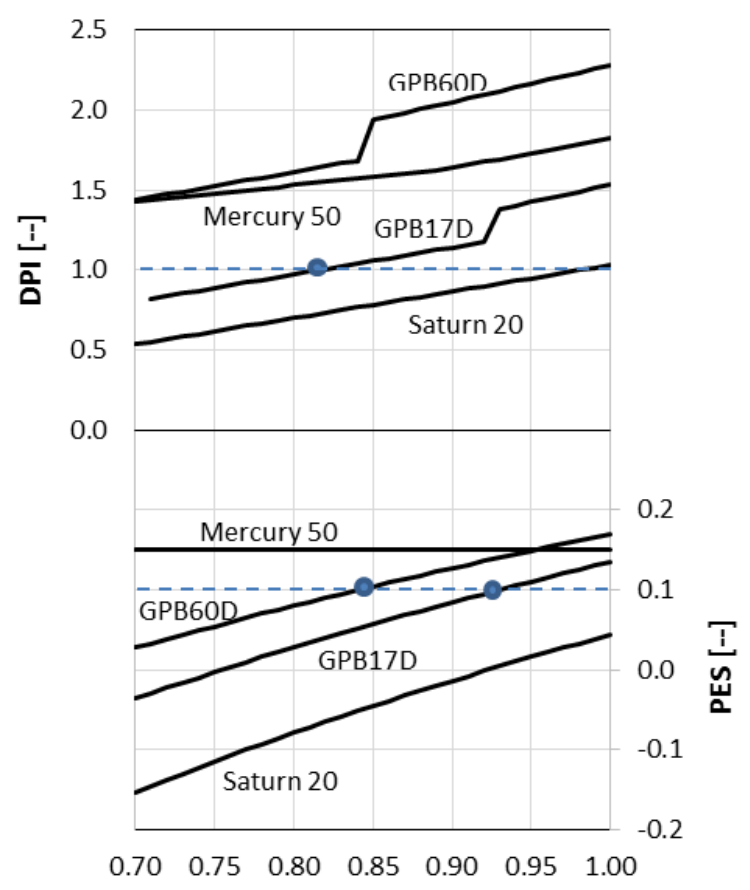

Heat Utilization Coefficient $\mathrm{u}_{\mathrm{H}}[--]$

Figure 3. DPI and PES versus heat utilization coefficient

A key parameter affecting plant economic performance is the heat utilization factor $u_{H}$, i. e. the fraction of producible heat actually used. Figure 3 shows PES and DPI trends versus $u_{H}$ for diverse plant arrangements. It can be noticed that the Saturn 20 based plant can reach a five year DPI equal to one $(P N V=0)$ only if the available heat is completely utilized. $u_{H}$ values below 0.9 leads to a negative PES, i.e. the CHP primary energy consumption is higher than that of separate generation. The GBP17D based plant (whose size is comparable to that of Saturn 20 one) shows a better performance. Zero PES is achieved at $u_{H}=0.75$. HEC threshold is reached at some $92 \%$ heat utilization. The step $D P I$ increase from 1.2 to 1.4 is due to incentives: the noticeable DPI 17\% improvement demonstrates the influence of HEC benefits on plant economic performance. GPB60D based plant (the larger size one) shows the best performance. Unitary DPI is achieved when about half of the available heat is used.

The Mercury 50 based plant deserves special consideration. It is the only plant with a design point cogeneration efficiency lower than 0.75 (see Table 3). Therefore calculations have been performed by splitting the plant into a cogeneration and a non-cogeneration part according to the procedure outlined in Section 3.

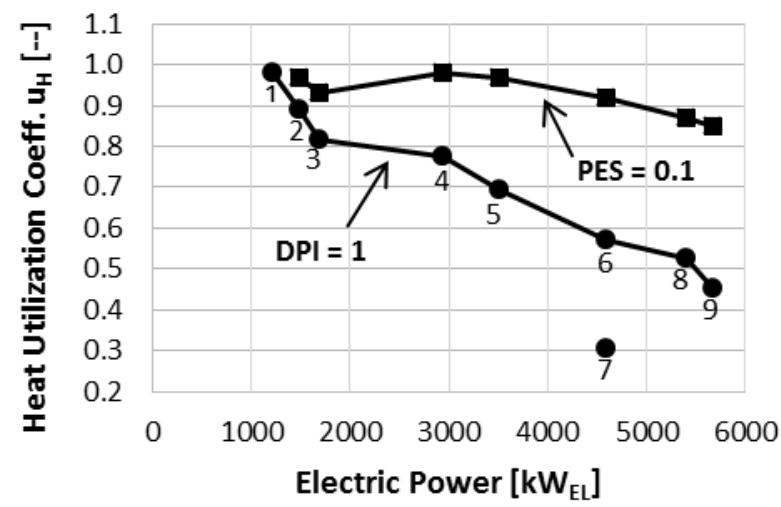

LEGEND: 1-Saturn 20; 2-GPB15D; 3- GPB17D; 4-GPB30D; 5-Centaur 40; 6 Centaur 50; 7-Mercury 50; 8-GPB60D; 9-Taurus 60

Figure 4. Minimum heat utilization values to achieve $P E S=$ 0.1 and $D P I=1$

The really high GT performance level (electrical efficiency equal to $38.5 \%$ ) and the high value of $E / H$ ratio lead to a constant noticeable PES value of 0.15 over a broad $u_{H}$ interval.

Therefore, in $u_{H}$ range considered in Figure 3, the DPI step increment is missing. Mercury 50 based plant economic performance is more than satisfactory. Anyway, the solar GT model Centaur 50 featured by the same installed power $(4,600 \mathrm{~kW})$ and by worst electrical performance shows a better economic result (see Figure 2 and Table 4). Moreover, lower size Solar GT Centaur $40\left(\eta_{E L, I S O}=27.9 \%\right)$ and Kawasaki GPB30D $\left(\left(\eta_{E L, I S O}=23.6 \%\right)\right.$ economic performances indexes are comparable to those of Mercury 50. This indicates that, if a sufficiently high heat utilization coefficient is ensured, GT electric performance is not so relevant in determining the economic result.

Finally, Figure 4 shows the minimum threshold values $u_{H}$ required to achieve $P E S=0.1$ (upper curve) and $D P I=1$ (lower curve). Plant sizes up $5,000 \mathrm{~kW}_{\mathrm{EL}}$ (apart the Mercury 50 based one) are eligible for HEC incentives only if the producible heat is almost completely used. Larger size plants show threshold values around 0.85 . Such high values are generally matched, according to data reported in [3]. Anyway, it must be stressed that the really high minimum threshold values presented by small size plants can easily lead to the loss of HEC benefits.

$u_{H}$ threshold values to achieve a five year unitary DPI are less severe. Only the two smaller plants show critical values. All the other plants are featured by threshold values close or lower than 0.8 . Higher size plants $\left(P_{E L, I S O} \geq 4,000 \mathrm{~kW} \mathrm{EL}\right)$ investment costs can be recovered in five years if only about one half of the available heat is actually used.

It has to be pointed out that unitary DPI is achieved without the contribution if incentives, with the exception of the Mercury 50 based plant. Taking into consideration that annual heat utilization factors higher than 0.8 are normally achieved [3], satisfactory pay-back times can be expected.

\section{CONCLUSIONS}

The convenience of installing small size (up to $6 \mathrm{MW}_{\mathrm{EL}}$ ) GT base CHP plants has been investigated taking the Italian regulatory and economic context into account. 
The study has been carried out taking into consideration plants arranged with commercially available GTs.

It has been found that economic performance is primarily affected by the specific plant investment costs and, secondarily, by GT technical features. As a results, the economic result significantly improves with the size of the plant.

Anyway, in case of a complete utilization of the producible heat almost all the CHP plants have proven their capability to achieve the HEC threshold limit and a 2-3 year pay-back time.

Results obtained by removing such a hypothesis have evidenced that plant sizes up $5 \mathrm{MW}_{\mathrm{EL}}$ can benefit from HEC incentives only if about $90 \%$ of producible heat is actually utilized. Such a severe requirement can easily lead to a failure to meet the HEC terms.

Less stringent heat utilization targets are required to achieve a five year return of the investment. Anyway, plant sizes lower than $1.5 \mathrm{MW}_{\mathrm{EL}}$ are featured by critical $u_{H}$ threshold values close or above 0.9. Higher sizes require targets below 0.8 , which are usually met in this kind of installations.

In general, provided that suitable conditions exist, small size GT based CHP in the range 1.5-6 $\mathrm{MW}_{\mathrm{EL}}$ can lead to relevant savings in respect to the purchase of electricity from the grid and the production of heat in a fueled boiler.

For lesser sizes, evaluations carried out on the basis of particular local conditions are recommended.

\section{REFERENCES}

[1] "DIRECTIVE 2004/8/EC of the European Parliament and of the Council of 11 February 2004," available: http://eur-lex.europa.eu/legalcontent/EN/ALL/?uri=CELEX\%3A32004L0008

[2] "Dati statistici sull'energia elettrica in Italia 2013," TERNA per SISTAN, 2014, available: http://www.comune.arezzo.it/il-comune/ufficio-servizidemografici/servizio-statistica-e-

censimenti/pubblicazioni-studi-rapporti/istat-altrepubblicazioni/terna-sistan.-dati-statistici-sullenergiaelettrica-in-italia.-2013/view

[3] "Rapporto statistico sulla cogenerazione. Periodo di osservazione 2013," GSE-Direzione Efficienza e Energia Termica- Unità Cogenerazione, 2015, available:http://www.gse.it/it/Qualifiche\%20e\%20certi ficati/GSE_Documenti/Certificati\%20Bianchi\%20e\%2
0CAR/Welcome\%20page/Documenti/Relazione\%20an nuale $\% 20$ sulla $\% 20$ cogenerazione $\% 20$ in $\% 20$ Italia $\% 20$ -\%20anno\%20produzione\%202013.pdf

[4] "Valutazione del potenziale nazionale di applicazione della cogenerazione e del teleriscaldamento efficiente," GSE, December 2015, available: http://www.gse.it/it/Dati\%20e\%20Bilanci/GSE_Docu menti/Studi/Potenziale\%20CAR\%20e\%20TLR.pdf

[5] G. Puglisi, F. Zanghirella, P. Ungaro, G. Cammarata, "A Methodology for the Genaration of Energy Consumption Profiles in the Residential Sector," Int J Heat \& Tech, vol. 34, no. 3, pp. 491-497, Sept., 2016. DOI: $10.18280 /$ ijht. 340320.

[6] G. Cannistraro, M. Cannistraro, A. Cannistraro, A. Galvagno and G. Trovato, "Evaluation on the convenience of a citizen service district heating for residential use. A new Scenario introduced by High Efficiency Energy Systems," Int J Heat \& Tech, vol. 33, no. 4, pp. 167-172, 2015. DOI: 10.18280/ijht.330421.

[7] "Decreto legislativo 8-2-2007 n. 20 Attuazione della direttiva 2004/8/CE sulla promozione della cogenerazione basata su una domanda di calore utile nel mercato interno dell'energia, nonché modifica alla direttiva 92/42/CEE," available: http://www.energia.provincia.tn.it/binary/pat agenzia energia/normativa/D.Lgs.\%208\%20febbraio\%202007, \%20n. 20.1227778118.pdf

[8] "Dati statistici sull'energia elettrica in Italia -2014. Nota di sintesi," TERNA, 2016, available: http://download.terna.it/terna/0000/0607/85.PDF

[9] "Decreto legislativo 4-8-2011," available: http://www.sviluppoeconomico.gov.it/images/stories/n ormativa/DM-4-AGOSTO-2011-2.pdf

[10] Gas Turbine World 2009 Handbook, Pequot Publishing Inc., Fairfield, CT, 2009.

[11] G. Cerri, M. Gazzino, F. A. Iacobone and A. Giovannelli, "Optimum planning of electricity production," Journal of Engineering for Gas Turbines and Power, vol. 131, no. 6, 1009.

[12] Foster-Pegg, R. W., "Capital Cost of gas-turbine heat recovery boilers," Chem. Eng., vol. 93, no. 14, pp. 7378, 1986.

[13] Decreto Legislativo 5-7-2011, available: http://www.sviluppoeconomico.gov.it/images/stories/n ormativa/DM-5-SETTEMBRE2011.pdf 